\title{
Korelasi Panjang Tulang Tibia Terhadap Tinggi Badan Pada Mahasiswa FK UMSU
}

\author{
Putra Diandro Utama Ritonga ${ }^{1}$, Hendra Sutysna ${ }^{2}$ \\ 1. Mahasiswa Fakultas Kedokteran Universitas Muhammadiyah Sumatera Utara \\ 2. Departemen Anatomi Fakultas Kedokteran Universitas Muhammadiyah Sumatera Utara
}

Korespondensi: hendrasutysna@umsu.ac.id

\begin{abstract}
ABSTRAK
Pendahuluan: Estimasi tinggi badan merupakan salah satu parameter penting dalam Antropologi forensik, dimana tinggi badan menjadi tindakan pertama dalam identifikasi. Rumus regresi menggunakan panjang tibia, jenis kelamin, dan usia mungkin memiliki perkiraan yang valid untuk tinggi badan yang membantu dalam konteks klinis.

Metode: Penelitian ini adalah penelitian deskriptif analitik dengan desain cross-sectional dilakukan pada 112 subjek terdiri dari kriteria inklusi dan eksklusi pria dan wanita. Sampel dipilih dengan teknik total sampling.

Hasil: Panjang tungkai Bawah (tulang Tibia) nilai korelasinya antara 0,48 dan $0,98(\mathrm{p}<0,001)$. Rumus regresi Thelinear menunjukkan Standard Error of the Estimate (SEE) berkisar antara 0,810 dan 3,49(p<0,001).

Kesimpulan: Ditemukan korelasi yang signifikan antara panjang tulang tibia dengan tinggi badan pada Mahasiswa Fakultas Kedokteran UMSU. Oleh karena itu, rumus regresi linier dapat diturunkan untuk estimasi tinggi badan dari panjang tibia.
\end{abstract}

Kata Kunci: panjang tibia, tinggi badan, rumus persamaan regresi, anthropometri.

\begin{abstract}
Introduction: Estimation of body height is one of the important parameter in the anthropology forensic, which the body height became the first action in identification. The regression formula using the tibia length, sex, and age might have valid approximation for body height which helpful in clinical context.

Methods: The analytic descriptive researchwith the cross-sectional design was done on 112 subject consist of male and female satisfy inclusion and exclusion criteria. Sample was selected by total sampling technique.

Results: Tibia length resulting correlation ranging between 0,488 and 0,968 ( $p<0,001)$. The linear regression formula showed Standard Error of the Estimate (SEE) ranging between 0,810 and 3,495 ( $p<0,001)$.

Conclusion: A significant correlation between tibia length and body heightwas found with a strong correlation. Hence, a linear regression formula was derived for the estimation of body height from tibia length.
\end{abstract}

Keywords: tibia length, body height, regression formula, anthropometry. 


\section{PENDAHULUAN}

Perkiraan tinggi badan individu merupakan karakter dan parameter penting untuk mengidentifikasi seseorang. Pada bencana yang melibatkan banyak korban seperti ledakan, kecelakaan pesawat terbang atau kereta api, identifikasi sulit dilakukan dengan cara biasa. Sering kali hanya tersedia potongan tubuh dengan tulang pada bagian tubuh yang tersisa sebagai petunjuk untuk melakukan identifikasi korban ${ }^{1}$. Perkiraan pertumbuhan dari panjang tulang atau ukuran bagian tubuh terus menjadi perhatian khusus bagi ahli forensik, ahli antropologi, ahli biologi, dan ahli geriatri. Tinggi seseorang yang merupakan jumlah panjang tulang dan bagian luar tubuh menunjukkan hubungan tertentu dalam bentuk proporsi dari jumlah pertumbuhan. Kedua peran tersebut sangat dibutuhkan baik dalam penelitian antropologis dan identifikasi yang diminta oleh ahli medikolegal ${ }^{2}$.

Beberapa penelitian telah dilakukan untuk menentukan estimasi pertumbuhan dari berbagai bagian tubuh seperti ekstremitas inferior dan superior, tulang panjang dan tulang pendek, kaki dan telapak kaki.

\section{METODE}

Penelitian ini menggunakan metode penelitian analitik korelatif dengan desain cross sectional. Populasi pada penelitian ini adalah mahasiswa program studi pendidikan dokter di Fakultas Kedokteran Universitas Muhammadiyah Sumatera Utara. Pengambilan sampel dilakukan dengan menggunakan metode total sampling, dimana sampel diambil dari seluruh mahasiswa aktif dengan kriteria inklusi yaitu telah berusia 21 tahun pada saat penelitian, bersedia mengikuti penelitian dengan menandatangani lembar informed consent, dan kriteria eksklusi berupa deformitas pada tungkai atau columna vertebralis, terdapat riwayat dislokasi atau fraktur pada tulang-tulang yang berpengaruh terhadap tinggi badan, terdapat riwayat dislokasi atau fraktur dan pernah menjalani terapi pembedahan pada tungkai bawah.

Penelitian ini akan dilaksanakan di

Fakultas Kedokteran Universitas

Muhammadiyah Sumatera Utara dengan pertimbangan kemudahan peneliti untuk mengambil data dan tersedianya sampel yang sesuai kriteria yang telah ditentukan. Tinggi badan diperoleh dengan mengukur jarak vertikal dari vertex ke lantai ketika kepala berada di posisi dataran Frankfurt dengan postur tegak tanpa alas kaki ${ }^{3}$. Titik medial paling dangkal di batas atas kondilus medial tibia sampai ujung malleolus medial ${ }^{4}$. Pengukuran dilakukan sebanyak tiga kali untuk menghindari kesalahan kemudian mencari rata-rata yang akan dicatat dan diolah pada tahap analisis data.

Data yang diperoleh adalah data numerik. Data diuji dengan uji korelasi Pearson, selanjutnya dianalisis dengan uji regresi linier untuk mendapatkan persamaan regresi.

\section{HASIL}

Frekuensi sampel yang diteliti berjumlah 112 orang dengan laki-laki sebanyak 68 orang $(60,7 \%)$, dan perempuan sebanyak 44 orang $(39,3 \%)$. Rata-rata panjang tulang tibia kanan laki-laki yaitu $37,642 \mathrm{~cm}$, rata-rata panjang tulang tibia kanan perempuan yaitu $34,772 \mathrm{~cm}$, sedangkan ratarata secara keseluruhan yaitu $36,207 \mathrm{~cm}$. Rata-rata panjang tulang tibia kiri laki-laki yaitu $37,352 \mathrm{~cm}$, rata-rata panjang tulang tibia kiri perempuan yaitu $34,715 \mathrm{~cm}$, sedangkan rata-rata secara keseluruhan yaitu $36,317 \mathrm{~cm}$. Rata-rata tinggi badan laki-laki yaitu $169,294 \mathrm{~cm}$, rata-rata tinggi badan perempuan yaitu $157,931 \mathrm{~cm}$, sedangkan ratarata secara keseluruhan yaitu $164,830 \mathrm{~cm}$. 
Setelah dilakukan uji linearitas dan hasilnya bersifat linier, maka dilakukan uji Pearson dan didapatkan hubungan antara panjang tulang tibia kanan dengan tinggi badan seperti pada Tabel 1 dan hubungan antara panjang tulang tibia kiri dengan tinggi badan seperti pada Tabel 2 .

Tabel 1. Hubungan panjang tulang tibia kanan

\begin{tabular}{cccc}
\multicolumn{4}{c}{ dengan tinggi badan } \\
\hline Jenis & Jumlah & $\begin{array}{c}\text { Korelasi } \\
\text { Pearson } \\
\text { Kelamin }\end{array}$ & $\mathbf{P}$ \\
\hline Laki-laki & 68 & 0,488 & $<0,001$ \\
Perempuan & 44 & 0,968 & $<0,001$ \\
Keseluruhan & 112 & 0,686 & $<0,001$ \\
\hline
\end{tabular}

Tabel 1 menunjukkan bahwa hubungan panjang tulang tibia kanan dengan tinggi badan pada laki-laki mempunyai nilai koefisien korelasi sebesar $0,488(\mathrm{p}<0,001)$, pada perempuan mempunyai nilai koefisien korelasi sebesar 0,968 ( $\mathrm{p}<0,001)$, dan secara keseluruhan mempunyai nilai koefisien korelasi sebesar 0,686 ( $<<0,001)$.

Tabel 2. Hubungan panjang tulang tibia kiri

\begin{tabular}{cccc}
\multicolumn{4}{c}{ dengan tinggi badan } \\
\hline $\begin{array}{c}\text { Jenis } \\
\text { Kelamin }\end{array}$ & Jumlah & $\begin{array}{c}\text { Korelasi } \\
\text { Pearson } \\
(\mathbf{r})\end{array}$ & $\mathbf{P}$ \\
\hline Laki-laki & 68 & 0.628 & $<0.001$ \\
Perempuan & 44 & 0.952 & $<0.001$ \\
Keseluruhan & 112 & 0.786 & $<0.001$ \\
\hline
\end{tabular}

Tabel 2 menunjukkan bahwa hubungan panjang tulang tibia kiri dengan tinggi badan pada laki-laki mempunyai nilai koefisien korelasi sebesar 0,628 ( $\mathrm{p}<0,001)$, pada perempuan mempunyai nilai koefisien korelasi sebesar 0,952 ( $\mathrm{p}<0,001)$, dan secara keseluruhan mempunyai nilai koefisien korelasi sebesar $0,786(p<0,001)$.

Perkiraan tinggi badan dari panjang tulang ulna didapatkan melalui analisis regresi linear. Analisis regresi tersebut akan menghasilkan persamaan yang dapat menghubungkan variabel bebas dengan variabel terikat. Variabel yang dapat dimasukkan kedalam uji regresi linear adalah variabel yang pada uji korelatif mempunyai nilai $\mathrm{p}<0,25$.

Seluruh hasil uji korelatif memiliki nilai $\mathrm{p}<0,001$ sehingga seluruh data memenuhi syarat untuk dilakukan uji regresi linear.

Tabel 3. Hasil uji analisis regresi linear

\begin{tabular}{|c|c|c|c|c|}
\hline & Variabel & Koefisien & $\begin{array}{l}\text { Standart } \\
\text { Error } \\
\text { Of the } \\
\text { Estimate }\end{array}$ & $\mathbf{P}$ \\
\hline \multirow{4}{*}{$\begin{array}{l}\text { Tinggi } \\
\text { badan } \\
\text { laki-laki }\end{array}$} & $\begin{array}{l}\text { Tulang } \\
\text { tibia } \\
\text { kanan }\end{array}$ & 1,214 & \multirow[t]{2}{*}{0,810} & \multirow[t]{2}{*}{$<.001$} \\
\hline & konstanta & 122,797 & & \\
\hline & $\begin{array}{l}\text { Tulang } \\
\text { tibia kiri }\end{array}$ & 1,192 & \multirow[b]{2}{*}{1,020} & \multirow[b]{2}{*}{$<.001$} \\
\hline & konstanta & 123,583 & & \\
\hline \multirow{3}{*}{$\begin{array}{l}\text { Tinggi } \\
\text { badan } \\
\text { Perempu } \\
\text { an }\end{array}$} & $\begin{array}{l}\text { Tulang } \\
\text { tibia } \\
\text { kanan }\end{array}$ & 2,185 & \multirow[t]{2}{*}{1,311} & \multirow[t]{2}{*}{$<.001$} \\
\hline & konstanta & 79,910 & & \\
\hline & konstanta & 84,907 & 1,563 & $<.001$ \\
\hline \multirow{3}{*}{$\begin{array}{l}\text { Tinggi } \\
\text { badan } \\
\text { Keseluru } \\
\text { han }\end{array}$} & $\begin{array}{l}\text { Tulang } \\
\text { tibia } \\
\text { kanan }\end{array}$ & 2,584 & 4,218 & $<.001$ \\
\hline & $\begin{array}{l}\text { Tulang } \\
\text { tibia kiri }\end{array}$ & 2,517 & \multirow[b]{2}{*}{3,495} & \multirow[b]{2}{*}{$<.001$} \\
\hline & konstanta & 73,223 & & \\
\hline
\end{tabular}

Berdasarkan hasil uji analisis regresi linear pada Tabel 3, dapat dirumuskan persamaan regresi linear yang menunjukkan estimasi hubungan panjang 
tulang tibia terhadap tinggi badan, sebagai berikut:

Pada sampel laki-laki:

a. $\quad$ Tinggi badan laki-laki $(\mathrm{cm})=122,797+$ $1,214 \times$ panjang tulang tibia kanan $(\mathrm{cm})$

b. Tinggi badan laki-laki $(\mathrm{cm})=123,583+$ $1,192 \times$ panjang tulang tibia kiri $(\mathrm{cm})$

Pada sampel perempuan:

a. Tinggi badan perempuan $(\mathrm{cm})=79,910$ $+2,185 \times$ panjang tulang tibia kanan (cm)

b. Tinggi badan perempuan $(\mathrm{cm})=84,907$ $+2,047 \times$ panjang tulang tibia kiri $(\mathrm{cm})$

Pada sampel keseluruhan:

a. Tinggi badan $(\mathrm{cm})=72,072+2,584 \mathrm{x}$ panjang tulang tibia kanan $(\mathrm{cm})$

b. Tinggi badan $(\mathrm{cm})=73,223+2,517 \mathrm{x}$ panjang tulang tibia kiri $(\mathrm{cm})$

\section{PEMBAHASAN}

Rata-rata panjang tulang tibia kanan dan kiri pada laki-laki lebih panjang daripada perempuan. Didapatkan juga rata-rata tinggi badan pada laki-laki lebih tinggi daripada perempuan. Hal ini sesuai dengan penelitian yang dilakukan oleh mahasiswa kedokteran Universitas Lambung Mangkurat ${ }^{41}$, penduduk lokal di eropa keturunan afrika selatan ${ }^{5}$, penduduk lokal di India Utara, India ${ }^{6}$, dan penduduk lokal di Thailand ${ }^{7}$. Sampai sekitar usia 10 tahun, anak perempuan cenderung lebih tinggi daripada anak laki-laki. Sejak usia 12 tahun, anak laki-laki sering mengalami pertumbuhan lebih cepat dibandingkan perempuan, sehingga kebanyakan laki-laki yang mencapai usia remaja lebih tinggi daripada perempuan.

Perempuan dewasa memiliki tulang yang lebih kecil dan lebih sedikit massa otot dibandingkan laki-laki dewasa ${ }^{8}$. Beberapa penelitian menunjukkan bahwa usia pubertas berkaitan dengan perbedaan jenis kelamin. Usia pubertas pada laki-laki terjadi dua tahun lebih lama dibandingkan perempuan sehingga memberikan waktu ekstra untuk proses pertumbuhan dan penambahan panjang tulang 9 .

Sampel laki-laki pada penelitian ini memiliki ukuran panjang tulang tibia kanan yang lebih panjang dibandingkan dengan panjang tulang tibia kiri. Hal yang serupa ditemukan pada sampel perempuan, dimana ukuran panjang tulang tibia kanan lebih panjang dibandingkan ukuran panjang tulang tibia kiri. Hasil pengukuran ini sesuai dengan penelitian yang dilakukan oleh mahasiswa kedokteran Universitas Lambung Mangkurat ${ }^{11}$, dan penelitian lainnya dengan sampel penduduk lokal di Eropa keturunan Afrika Selatan ${ }^{12}$.

Berbagai penelitian antropometri yang membandingkan kedua sisi bagian tubuh manusia menunjukkan adanya perbedaan ukuran antara bagian kanan dan kiri tubuh. Perbedaan ukuran antara bagian kanan dan kiri tubuh yang konsisten pada sebuah individu ditemukan pada individu yang bertulang belakang yang diberi istilah asimetris ${ }^{10}$.

Hubungan panjang kedua tulang tibia dengan tinggi badan mempunyai korelasi sedang sampai kuat $[0,488$ - 0,786] hingga sangat kuat $[0,952-0,968]$. Hasil ini sesuai dengan penelitian yang dilakukan oleh mahasiswa Fakultas Kedokteran Universitas Lambung Mangkurat ${ }^{11}$, serta penelitian lainnya dengan sampel penduduk lokal di Thailand $^{12}$. Sementara itu, penelitian yang dilakukan oleh mahasiswa Fakultas Kedokteran dan Ilmu Kesehatan Universitas Warmadewa menunjukkan adanya korelasi yang kuat antara panjang tulang tibia dengan tinggi $\operatorname{badan}^{13}$. Demikian pula penelitian lainnya yang menggunakan sampel penduduk lokal Eropa keturunan Afrika Selatan ${ }^{12}$.

Prediksi tinggi badan dapat dilakukan dengan menemukan regresi khusus. Pada penelitian ini, Penulis menemukan rumus 
persamaan regresi linear yang dapat memperkirakan tinggi badan berdasarkan panjang tulang tibia. Persamaan tersebut mempunyai Standart Error of the Estimate (SEE) yang berkisar antara 0,810 hingga 4,218 . SEE merupakan parameter yang baik dalam hal menunjukkan hubungan antara nilai asli dan nilai perkiraan. Semakin kecil nilai SEE maka semakin akurat persamaan regresi linear tersebut ${ }^{14}$. Sampel laki-laki memiliki nilai SEE yang paling rendah $(0,810-1,020)$. Hasil ini menunjukkan bahwa persamaan regresi linear pada sampel laki-laki menunjukkan hasil yang lebih akurat dibandingkan pada sampel perempuan maupun sampel keseluruhan. Hasil ini sesuai dengan penelitian yang dilakukan di penduduk lokal India Utara, India, dimana pada penelitian tersebut sampel laki-laki memiliki nilai SEE yang paling rendah ${ }^{13}$.

Hasil persamaan regresi linear yang diperoleh dari penelitian ini hanya dapat diterapkan pada populasi penelitian ini. Hal tersebut terjadi karena pada penelitianpenelitian sebelumnya menyatakan bahwa berbagai pengukuran kaki cenderung berbeda antara satu daerah dengan daerah lain, demikian juga antara satu kelompok suku dengan suku lainnya. Dengan demikian, persamaan regresi linear yang ditemukan untuk memperkirakan tinggi badan dari suatu kelompok suku pada suatu populasi tidak dapat digunakan untuk memperkirakan tinggi badan dari kelompok suku yang lain ${ }^{15}$.

\section{KESIMPULAN}

Dari hasil penelitian diperoleh bahwa terdapat hubungan yang signifikan antara panjang tulang tibia dengan tinggi badan pada mahasiswa Fakultas Kedokteran Universitas Muhammadiyah Sumatera Utara dengan koefisien korelasi yang cukup kuat, sehingga tinggi badan dapat diperkirakan dengan mengukur panjang tulang tibia melalui persamaan regresi linear.

\section{UCAPAN TERIMA KASIH}

Penulis mengucapkan terima kasih kepada semua pihak yang telah membantu terlaksananya penelitian ini, baik yang terlibat secara langsung maupun tidak langsung.

\section{DAFTAR PUSTAKA}

1. Gupta P, Kumar P, Gaharwar A, Ansari H, Hussein M. Correlation of Percutaneous Length of Tibia with Body Height and Estimation of Stature in Living North Indian Males. Sch. J. App. Med. Sci. 2014; 2(2D):848-852

2. Duyar I, Pelin C. Body Height Estimation Based on Tibia Length in Different Stature Groups. American Journal Of Physical Anthropology. 2003; 122:23-27.

3. Bidmos MA. Estimation of fragmentary femora in indegenous South Africans. International Journal of Legal Medicine. 2008; 122: 293-299.

4. Agrawal J, Raichandani L, Kataria SK, Raichandani S. Estimation of stature from hand length and length of phalanges. Journal of Evolution of Medical and Dental Sciences. 2013 December 16; 2(50): 9651-9656.

5. Chibba K, Bidmos MA. Using tibia fragments from south african of European descent to estimate maximum tibia length and stature. Forensic Science International 2007; 169: 145-151

6. Gupta P, Kumar P, Gaharwar A, etc. Correlation of percutaneous length of tibia with body height and estimation of stature in living north indian males. Sch. J. App. Med. Sci 2014; 2(2D): 848-852

7. Mahakkanukrauh $\mathrm{P}$, Khanpetch $\mathrm{P}$, Prasitwattanseree S. Stature estimation from long bone lengths in a thai population. Forensic Science International 2011; 210: 279.e1-279.e7.

8. Wilujeng I.D. Korelasi antara panjang tulang radius dengan tinggi badan pada 
pria dewasa suku lampung dan suku Jawa di Kecamatan Gisting Kabupaten Tanggamus. Fakultas Kedokteran Universitas Lampung; 2016.

9. Krishan K, Sharma A. Etimation of stature from dimension of hands and feet in North Indian population. Journal Forensic Legal Medicolegal. 2007; 14; 327-332.

10.Barut C, Sevinc O, Sumbuloglu V. Evaluation of hand asymetry in relation to hand preference. Coll antropol. 2009; 35 (4); 1119-24

11.Aflanie I. Perbandingan korelasi penentuan tinggi badan antara metode pengukuran panjang tibia perkutaneus dan panjang telapak kaki. Mutiara Medika. 2011; 11(3): 201-206.

12.Mahakkanukrauh $\mathrm{P}$, Khanpetch $\mathrm{P}$, Prasitwattanseree S. Stature estimation from long bone lengths in a thai population. Forensic Science International 2011; 210: 279.e1-279.e7.

13.Putu Sana IGN, dkk. Perkiraan tinggi badan berdasarkan tulang panjang usia 1722 tahun. WMJ 2016; 1(2): 66-70.

14.Ozaslan A, Karadayi B, Kolusayin M.O, Kaya A, Afssin H. Predictive role of hand and foot dimensions in stature estimation. Romanian Society of Legal Medicine. 2012; 20; 41-46.

15.Ilayperuma I, Nanayakkara G, Palahepitiya N. Prediction of personal stature based on the hand lenght. Galle Medical Journal. 2009; 14 (1); 15-18. 